\title{
Padlet: el uso de la pizarra colaborativa on-line en estudios de grado
}

\section{Francesc A. Esteve-Turrillas, Sergio Armenta}

Departamento de Química Analítica, Universitat de València, Edificio Jeroni Muñoz, c/ Dr. Moliner 50, 46100 Burjassot, España (francesc.a.esteve@uv.es, sergio.armenta@uv.es)

\begin{abstract}
This communication shows two applications of the padlet virtual board to develop both specific and transversal skills in the study of Degree in Chemistry and Degree in Food Science and Technology. The use of virtual walls allows students to select and expand content related to the subject, as well as facilitate the divulgation and comment of these in a common place to all students of the subject. Finally, data on the utility and degree of satisfaction obtained through an opinion survey were included.
\end{abstract}

\section{Keywords: Padlet, virtual wall, collaborative blackboard, active learning.}

\section{Resumen}

En la presente comunicación se muestran dos aplicaciones del empleo de la pizarra virtual padlet para desarrollar competencias tanto específicas como transversales en estudio de Grado en Química y Grado en Ciencia y Tecnología de los Alimentos. El empleo de pizarras virtuales permite el alumno seleccionar y ampliar contenidos relacionados con la asignatura, así como facilitar la divulgación y el comentario de estos en un lugar común a todos los alumnos de la asignatura. Finalmente, se incluyen datos de la utilidad y grado de satisfacción obtenidos a través de una encuesta de opinión.

Palabras clave: Padlet, muro virtual, pizarra colaborativa, aprendizaje activo.

\section{Introducción}

El desarrollo tecnológico y las nuevas formas de comunicación obligan a un replanteamiento de la práctica docente. Cada vez aumenta en mayor grado el espacio dedicado a las tecnologías digitales de la información y la comunicación en los procesos educativos universitarios, siendo necesarias una readaptación continua de los procesos de enseñanza aprendizaje, así como nuevas funciones y roles para el profesorado y los estudiantes (Palomo-López, 2007). Con todo ello, no se pretende, de ninguna forma, introducir procesos más sofisticados y/o complejos, sino de adaptarse a la forma de pensar y actuar de los estudiantes actuales a la vez que se valoran las posibilidades didácticas de diferentes herramientas didácticas disponibles en la actualidad. Debemos por tanto, plantearnos la siguiente reflexión ¿Qué se entiende por aprendizaje, cómo se produce y cómo podemos mejorarlo mediante el uso de herramientas tecnológicas? Está claro, que el 
estudiante universitario actual, gracias a internet, tiene a su disposición (inmediata) más información de la que puede procesar, por tanto, los procesos de enseñanza/aprendizaje no deberían estar tan centrados en facilitar la información sino dotar al estudiante de las herramientas adecuadas para procesar dicha información, consiguiendo que los estudiantes tengan un espíritu crítico que les permita seleccionar, procesar, analizar y sacar conclusiones de la información que tiene a su alcance. Este cambio en los objetivos supone un cambio del papel del profesor y también del alumno. El primero deja de ser un mero transmisor de conocimiento y pierde protagonismo en favor del estudiante, que deja de ser un sujeto pasivo, con un papel puramente receptivo, para tener ahora un papel mucho más activo en el proceso de enseñanza aprendizaje. En este sentido desplazamos el foco de la enseñanza y nos centramos en el aprendizaje (Bergman et al., 2014).

Una de las herramientas digitales que facilita este cambio de visión es el uso de murales o pizarras digitales. Estas pizarras virtuales se construyen empleando una metodología socioconstructivista en la que se promueve la colaboración frente a la competencia, las redes de trabajo (networks) frente al individualismo, que les permita alcanzar las competencias básicas y además las trasversales. De esta forma se pretende fomentar el aprendizaje activo, por descubrimiento y significativo que permita adaptarse a las necesidades educativas del alumnado.

Existen varias herramientas en la actualidad para realizar murales o pizarras virtuales entre las que podemos destacar Prezi, Smore, Pooplet, Mural.ly, Padlet, Lino o Glogster (Hernández et al., 2014).

En esta comunicación se ha utilizado Padlet como herramienta educativa para crear pizarras virtuales, brindando la posibilidad de cargar y compartir diversos contenidos multimedia como esquemas, imágenes, audios y videos en un muro de entorno digital. La herramienta contribuye a la creación de contenidos de forma colaborativa, funcionando como pizarra virtual (Gonzalez-Frías et al., 2015). La aplicación ofrece un panel en blanco fácilmente configurable en función de las necesidades y propósitos docentes de cada asignatura. En dicho panel, tanto profesor como alumnos pueden puede seleccionar los elementos que desean guardar, que pueden ser de diferentes formatos: imágenes, videos, caricaturas, archivos doc o pdf, etc. de creación propia o encontrados en internet. Por tanto, padlet puede considerarse una herramienta de edición abierta orientada a la construcción colaborativa de contenidos.

Una de las ventajas claras que aporta padlet es la generación de contenidos mediante trabajo coordinado y su facilidad de actualización y revisión permanente. Además de ser un espacio de trabajo colaborativo, las pizarras creadas en padlet pueden considerarse como objetos de múltiple autoría, de forma que los propios estudiantes sean los creadores de conocimiento.

\section{Objetivos}

El objetivo principal de esta comunicación es crear una pizarra virtual en la que tanto estudiantes como profesor puedan intercambiar información, ideas, imágenes y videos 
fomentando el aprendizaje activo y colaborativo. En dicha pizarra interactiva los estudiantes tendrán a su disposición información generada por ellos mismos que les facilitará alcanzar los resultados de aprendizaje definidos en las guías docentes de las asignaturas. Este objetivo principal se puede dividir en los siguientes objetivos específicos:

- Saber utilizar Internet para buscar información y recursos en la preparación de las clases y complementar los contenidos de la asignatura.

- Conocer páginas de Internet (portales, páginas web, revistas electrónicas, diccionarios, buscadores...) relativos a su especialidad y compartirlos con sus compañeros para crear un temario específico de la asignatura en la que ellos contribuyen en la búsqueda de contenidos.

- Fomentar el empleo de nuevas herramientas disponibles en Internet para comunicarse con sus compañeros (correo electrónico, listas de distribución, foros...) y crear un entorno educativo común con sus compañeros.

\section{Desarrollo de la innovación}

\subsection{Química General II - Grado en Química}

\subsubsection{Contexto de aprendizaje}

La asignatura de Química General II se imparte en el segundo cuatrimestre del primer curso del grado en Química. El número de estudiantes matriculados es de 220-240 divididos en cuatro grupos de 60 estudiantes aproximadamente. Respecto a los resultados académicos cabe destacar que el porcentaje de estudiantes aprobados respecto a matriculados es de $56 \%$ en el periodo comprendido entre 2010-17, siendo el 59\% el correspondiente al año 20162017. La asignatura incluye 51 horas de clases de teoría, 9 horas de tutorías regladas, 12 horas de elaboración de trabajos en grupo, 54 horas de estudio y trabajo autónomo y 24 horas de preparación de actividades de evaluación.

\subsubsection{Contenidos de la asignatura}

La descripción de los contenidos de la asignatura Química General II es la siguiente, conforme se indica en la Guía Docente de la asignatura:

Tema 1. Energía de las reacciones químicas

Tema 2. La dirección del cambio químico

Tema 3. El equilibrio en las reacciones químicas

Tema 4. Cambios de estado de sustancias puras

Tema 5. Disoluciones

Tema 6. Equilibrio ácido-base

Tema 7. Equilibrios de formación de complejos

Tema 8. Equilibrios de solubilidad 
Tema 9. Equilibrios de oxidación-reducción

Tema 10. La velocidad del cambio químico

\subsubsection{Descripción de la tarea}

Se ha creado una pizarra virtual usando Padlet para almacenar, visualizar y comentar videoresúmenes, de dos minutos de duración, creados por los propios estudiantes (distribuidos en grupos) de los diferentes temas de la asignatura. Esta tarea se ha realizado siguiendo el esquema propuesto:

- Clases magistrales participativas (dependiendo del tema seleccionado el número de sesiones puede variar entre 3-6).

- Seminario, donde el docente explica el interés de la creación de un mural virtual para añadir los video-resúmenes de los diferentes temas de la asignatura y la posibilidad de comentar y discutir los videos generados. En esta sesión, se explica y se definen claramente los objetivos de la tarea y los resultados esperados junto con la evaluación de dichos video resúmenes.

- Tutorías grupales (mínimo 2/3 sesiones), seguimiento del proceso de realización del video y comentario de las discusiones generadas en la pizarra virtual.

- Seminario, visionado y evaluación de los video-resúmenes finales.

La evaluación del/los objeto/s generados se realizará mediante rúbricas. De esta forma se pretende que los alumnos sean conocedores de los diferentes niveles de cumplimiento de la actividad o de parte de ella, desde lo considerado como insuficiente hasta lo excelente. La evaluación de dicha actividad forma parte de la evaluación de las sesiones de tutorías grupales, seminarios y elaboración de trabajos. El porcentaje en el que la actividad expuesta contribuye a la nota final es un 25 \%, que se obtendrá como media de la evaluación del profesor y la evaluación del resto de grupos (compañeros de clase).

Adicionalmente, se han realizado encuestas tanto a los estudiantes como a los docentes para establecer el grado de satisfacción con la pizarra creada así como la utilidad de los materiales elaborados.

\subsubsection{Resultados de la actividad y grado de satisfacción}

A continuación se muestran parte de los resultados obtenidos durante la preparación del material definitivo, junto con el número de alumnos implicados en la actividad y su grado de participación.

En el Padlet creado por los estudiantes de la asignatura Química General II (ver Figura 1) se ha optado por crear un mural distribuido en columnas en los que debajo de cada columna se pueden encontrar los video-resúmenes creados por los estudiantes de los diferentes cursos (2016/17 y 2017/18), además de otra columna en los que se han añadido ejemplos representativos de la actividad en cuestión obtenidos de YouTube.

Los alumnos han realizado un total de 9 video-resúmenes; 2 del tema 1 (Energía de las reacciones químicas), 2 del tema 2 (La dirección del cambio químico), 1 del tema 3 (El

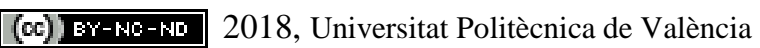

Congreso IN-RED (2018) 
equilibrio en las reacciones químicas), 1 del tema 4 (Cambios de estado de sustancias puras) y 3 del tema 5 (Disoluciones).

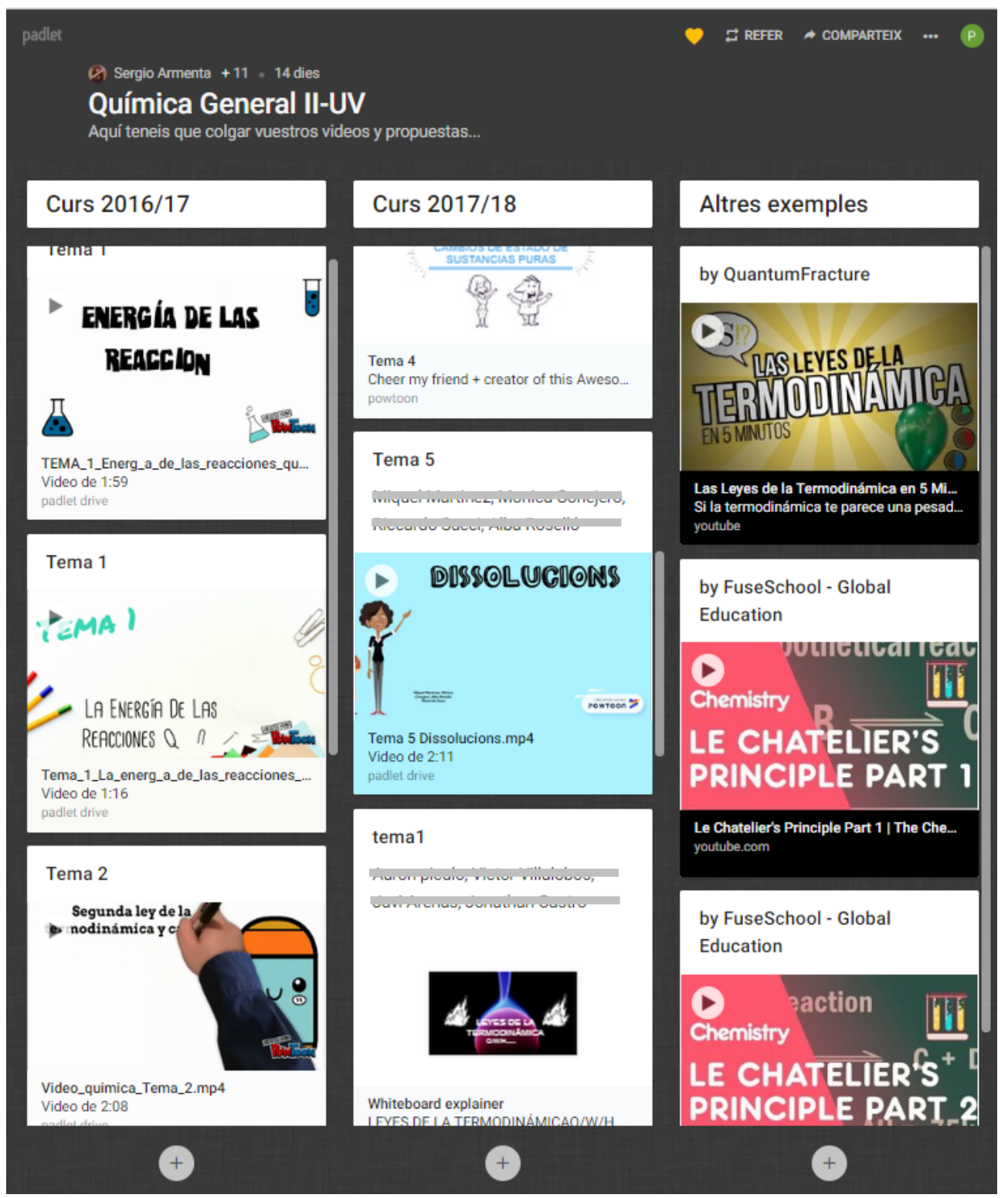

Fig. 1 Esquema de los diferentes video-resúmenes generados ordenados en función del curso.

Para conocer el grado de satisfacción de los estudiantes con la actividad realizada se les pasó al final de la misma una encuesta de evaluación con las preguntas que se pueden observar en la Tabla 1.

El tiempo dedicado por la mayoría de los alumnos (72\%) para la realización de los microvideos fue de 5 a 10 horas, mientras que un $22 \%$ empleó de 2 a 5 horas y un 6 \% más de 10 horas. En cuanto al tiempo dedicado al visionado de videos realizados por sus 
compañeros la mayoría de los alumnos emplearon de 10 a 30 min (50\%) y entre 30 y 60 min (22\%), mientras que un leve 3\% dedicó más de 1 hora al visionado de videos de compañeros. Sin embargo un 25 \% manifestó haber empleado menos de 10 minutos indicando un mínimo interés por la participación en dicha actividad. Respecto a la utilidad de los videos disponibles en el padlet de la asignatura, la gran mayoría de los alumnos indicaron que les había ayudado algunas veces (50\%) y muchas veces (38\%) en la mejor comprensión del tema correspondiente. La encuesta realizada indicó que el estudiante percibe muchas veces (23\%) y algunas veces (61\%) que la información está más accesible a través del empleo de pizarras virtuales, mientras que un $16 \%$ de los estudiantes no percibió mejora en la accesibilidad. El 57 \% de los alumnos encuestados nunca o casi nunca (23 \%) había utilizado pizarras electrónicas tipo padlet en alguna otra asignatura y el 80\% de ellos se muestra de acuerdo o totalmente de acuerdo en utilizarlas en otras asignaturas.

Tabla 1. Porcentaje de respuestas obtenidas en la encuesta realizada sobre la actividad.

\begin{tabular}{|c|c|c|c|c|}
\hline & $>10 h$ & $5-10 h$ & $2-5 h$ & $<2 \mathbf{h}$ \\
\hline \multicolumn{5}{|l|}{$\begin{array}{l}\text { ¿Cuánto tiempo has dedicado a la } \\
\text { realización de vídeo? }\end{array}$} \\
\hline & $>1 \mathrm{~h}$ & $30-60 \mathrm{~min}$ & 10-30min & $<10 \mathrm{~min}$ \\
\hline \multicolumn{5}{|l|}{$\begin{array}{l}\text { ¿Cuánto tiempo has dedicado al } \\
\text { visionado de vídeos de compañeros } \\
\text { publicado en padlet? }\end{array}$} \\
\hline & $\begin{array}{l}\text { Totalmente } \\
\text { de acuerdo }\end{array}$ & De acuerdo & En desacuerdo & $\begin{array}{c}\text { Muy en } \\
\text { desacuerdo }\end{array}$ \\
\hline \multicolumn{5}{|l|}{$\begin{array}{c}\text { ¿Crees que el microvideo ayuda a } \\
\text { comprender mejor este tema de la } \\
\text { asignatura? }\end{array}$} \\
\hline \multicolumn{5}{|l|}{$\begin{array}{l}\text { ¿Crees que la información está más } \\
\text { accesible en el muro virtual de padlet? }\end{array}$} \\
\hline \multicolumn{5}{|l|}{$\begin{array}{c}\text { ¿Emplearías pizarras electrónicas tipo } \\
\text { padlet en alguna otra asignatura? }\end{array}$} \\
\hline & $\begin{array}{l}\text { Muchas } \\
\text { veces }\end{array}$ & $\begin{array}{l}\text { Algunas } \\
\text { veces }\end{array}$ & Casi nunca & No nunca \\
\hline $\begin{array}{c}\text { ¿Has empleado con anterioridad algún } \\
\text { tipo de pizarra electrónica? }\end{array}$ & & & & \\
\hline
\end{tabular}

\subsection{Transformación y Conservación - Grado en Ciencia y Tecnología de los Alimentos}

\subsubsection{Contexto de aprendizaje}

Transformación y conservación es una asignatura obligatoria anual que se imparte en el segundo curso del Grado de Ciencia y Tecnología de los Alimentos que se imparte en la Facultad de Farmacia de la Universitat de València. La asignatura incluye 72 créditos ECTS distribuidos en 82 horas de teoría, 25 horas de prácticas de laboratorio, 4 horas de seminarios coordinados y 4 horas de tutorías presenciales. La asignatura se imparte con una frecuencia de 4 horas semanales en el primer semestre y 5 horas semanales en el segundo. El número de alumnos en el curso 2016-2017 fue de 38. La asignatura se imparte en un aula con asientos y mesas fijos con una capacidad de 120 personas.

\subsubsection{Contenidos de la asignatura}

2018, Universitat Politècnica de València

Congreso IN-RED (2018) 
Los contenidos que refleja la guía docente de la asignatura Transformación y Conservación se distribuyen en 8 bloques con un total de 27 temas.

Bloque 1. Introducción

Tema 1. Introducción a la tecnología de los alimentos

Tema 2. Causas de alteración de los alimentos

Tema 3. Las industrias de producción de alimentos

Tema 4. Operaciones de acondicionamiento de materias primas

Bloque 2. Operaciones de transformación de alimentos

Tema 5. Modificación de tamaño. Mezclado. Emulsificación

TEMA 6. Operaciones de separación

TEMA 7. Operaciones de modificación de la textura

Bloque 3. Métodos térmicos de conservación

Tema 8. Bases de la conservación de alimentos por el calor

Tema 9. Cálculo y ajuste del tratamiento térmico

Tema 10. Instalaciones para el tratamiento térmico y su aplicación

Bloque 4. Conservación de alimentos por frío

Tema 11. La refrigeración de los alimentos

Tema 12. Conservación de alimentos por congelación

Tema 13. Métodos y equipos de congelación de alimentos

Bloque 5. Conservación por depresión de la actividad de agua

Tema 14. Fundamentos sobre la depresión de la actividad de agua

Tema 15. Deshidratación de alimentos

Tema 16. Equipos e instalaciones de deshidratación de alimentos

Tema 17. Conservación por concentración

Bloque 6. Tecnologías emergentes de conservación

Tema 18. Conservación por atmósferas modificadas

Tema 19. Conservación por radiaciones ionizantes

Tema 20. Altas presiones hidrostáticas

Tema 21. Pulsos eléctricos de alto voltaje

Tema 22. Nuevas tecnologías de conservación

Bloque 7. Tecnología culinaria

Tema 23. El horneado y el asado

Tema 24: La fritura y el tostado

Tema 25. Microondas

Bloque 8. Envasado de alimentos

Tema 26. Sistemas de llenado y envasado de alimentos

Tema 27. Envases activos

(cc) EY-NC-ND 2018, Universitat Politècnica de València

Congreso In-Red (2018) 


\subsubsection{Descripción de la tarea}

En esta asignatura se ha empleado padlet como medio para publicar información relativa al procesado de alimentos en una pizarra virtual común a todos los estudiantes. Durante el desarrollo de la asignatura en las clases teóricas se imparten conocimientos relacionados con las operaciones necesarias para el acondicionamiento, conservación, cocinado y envasado de alimentos. En los últimos meses en que se imparte la asignatura resulta muy adecuado mostrar a los alumnos vídeos que muestren el proceso de elaboración de distintos alimentos, para indicar las variadas operaciones que se incluyen en el proceso completo y discutir su idoneidad y las ventajas o inconvenientes que presentan. En este sentido, el empleo de pizarras virtuales, como padlet, permite a los alumnos compartir videos (obtenidos principalmente a través de YouTube) relacionados con el procesado de alimentos. De esta forma los alumnos participan activamente en la elección del tipo de alimento a estudiar, lo que constituye una motivación extra a la hora de relacionar los contenidos de la asignatura con la fabricación de alimento propuesto. Adicionalmente, la plataforma padlet no solo permite incluir material multimedia, sino que también permite incluir comentarios de los videos que se han añadido, lo que permite al profesor proporcionar un feedback rápido al alumno y fomentar la discusión de los aspectos más relevantes.

El desarrollo de esta actividad se temporaliza en el segundo semestre, donde se realizan dos tutorías de una hora de duración cada una. En la primera tutoría se explica al alumno cual es el fundamento de la actividad propuesta, explicando detenidamente el funcionamiento de la herramienta padlet y las ventajas que presenta. A partir de ese momento, el profesor cuelga videos en el padlet común para que el alumno se familiarice con el empleo de esta pizarra electrónica y se fomenta que los alumnos realicen comentarios acerca de la temática expuesta en los videos. En esta etapa es donde se incita al alumno a participar activamente en la búsqueda y publicación de videos adicionales. Esto permite al profesor hacer referencia directa a los videos publicados por los alumnos, durante la impartición de las clases de teoría, relacionándolos con los contenidos teóricos que se imparten. La Figura 2 muestra el contenido de la pizarra electrónica padlet creada para la asignatura Transformación y Conservación en el curso 2017-2018.

\subsubsection{Resultados de la actividad y grado de satisfacción}

La evaluación del trabajo realizado en las tutorías del segundo semestre presenta un 5 \% de la nota final. La evaluación de esta actividad se centrará en la participación del alumno, tanto en la publicación de videos, como en el comentario de videos publicados por otros compañeros. Para obtener un aprobado en la actividad propuesta el alumno debe publicar al menos un vídeo y comentar un video de un compañero. La nota máxima se otorgará a aquellos alumnos que publiquen más de un video y realicen más de un comentario de videos de compañeros. En este caso el profesor puede actuar de moderador de la pizarra electrónica, eliminando aquellos videos improcedentes y comentando aquellos que no se ajusten al objetivo propuesto. Adicionalmente, se ha realizado una encuesta opcional (ver

(cc) EY-NC-ND 2018, Universitat Politècnica de València

Congreso IN-RED (2018) 
Tabla 1) para establecer el grado de evolución y el grado de satisfacción de los alumnos relacionado con el empleo de la pizarra electrónica padlet como medio de difusión de contenidos multimedia, siendo el número de encuestas recogidas 34 .

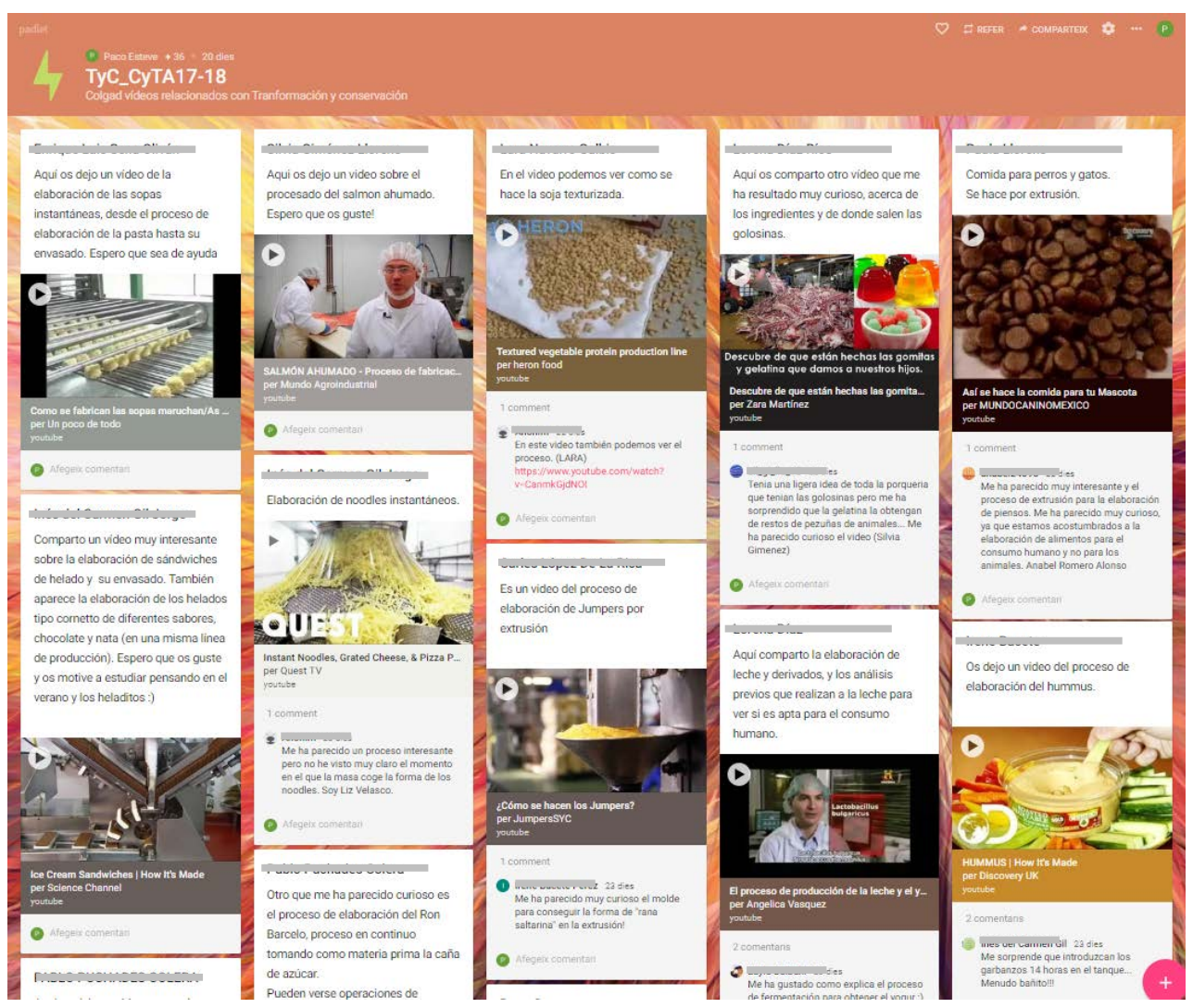

Fig. 2 Pizarra electrónica padlet creada para la asignatura Transformación y Conservación (https://es.padlet.com/paco_esteve_turrillas/TyC1718).

En primer lugar se observa que los tipos de dispositivos electrónicos más frecuentemente empleados para buscar contenidos en internet fueron el ordenador portátil y el Smartphone, siendo el Smartphone más empleado en la búsqueda de contenidos generales (45\%) y el portátil en la búsqueda de contenidos relacionados con el Grado en Ciencia y Tecnología de Alimentos (71\%). Respecto al lugar donde se buscan contenidos en internet cabe destacar el elevado porcentaje obtenido en casa tanto para las búsquedas de contenidos generales (70\%) como de contenidos relacionados con la asignatura (66\%); mientras en segundo lugar figura la Universidad (19 y 29 \%, respectivamente). El tiempo dedicado a la búsqueda de vídeos en internet relacionados con la fabricación de alimentos es menos de una hora para el 33\%, entre 1 y 2 horas para el 48\%, y más de 2 horas para el $18 \%$. Tiempos ligeramente inferiores se han dedicado al visionado de vídeos publicados en padlet por compañeros, menos de una hora para el 55\%, entre 1 y 2 horas para el $42 \%$, y más de 2 horas para solo un $3 \%$. Los alumnos también autoevaluaron su propio trabajo indicando tanto el número de videos publicados en el padlet como el número de comentarios de videos de compañeros. La gran mayoría publicó un video (76 \%) y un comentario (62 \%), 
mientras que un 24 \% publicó más de un video y un 33\% hizo más de un comentario. Cabe destacar que 2 alumnos (6\%) no hicieron ningún comentario a videos de compañeros, a pesar que era obligatorio para obtener el aprobado en esta actividad.

Tabla 2. Encuesta de grado de satisfacción de la actividad propuesta para la asignatura Transformación y Conservación.

\begin{tabular}{|c|c|c|c|c|}
\hline & PC & PC portátil & Tablet & Smartphone \\
\hline \multicolumn{5}{|l|}{$\begin{array}{l}\text { ¿Qué dispositivo electrónico empleas más } \\
\text { frecuentemente para buscar contenidos } \\
\text { generales en internet? }\end{array}$} \\
\hline \multicolumn{5}{|l|}{$\begin{array}{l}\text { ¿Qué dispositivo electrónico empleas más } \\
\text { frecuentemente para buscar contenidos en } \\
\text { internet relacionados con Tecnología de } \\
\text { Alimentos? }\end{array}$} \\
\hline & Casa & Universidad & $\begin{array}{l}\text { Medio de } \\
\text { transporte }\end{array}$ & Calle \\
\hline \multicolumn{5}{|l|}{$\begin{array}{c}\text { ¿Dónde buscas contenidos generales en } \\
\text { internet? }\end{array}$} \\
\hline \multicolumn{5}{|l|}{$\begin{array}{l}\text { ¿Dónde buscas contenidos en internet } \\
\text { relacionados con Tecnología de Alimentos? }\end{array}$} \\
\hline & $<\mathbf{1 h}$ & $1-2 h$ & $2-5 h$ & $>5 h$ \\
\hline \multicolumn{5}{|l|}{$\begin{array}{l}\text { ¿Cuánto tiempo has dedicado a la } \\
\text { búsqueda de vídeos en internet? }\end{array}$} \\
\hline \multicolumn{5}{|l|}{$\begin{array}{l}\text { ¿Cuánto tiempo has dedicado al visionado } \\
\text { de vídeos de compañeros publicado en } \\
\text { padlet? }\end{array}$} \\
\hline & 0 & 1 & 2 & $>2$ \\
\hline \multicolumn{5}{|l|}{$\begin{array}{l}\text { ¿Cuántos videos has publicado en el padlet } \\
\text { de la asignatura? }\end{array}$} \\
\hline \multicolumn{5}{|l|}{$\begin{array}{c}\text { ¿Cuántos comentarios has realizado en el } \\
\text { padlet de la asignatura? }\end{array}$} \\
\hline & $\begin{array}{l}\text { Totalmente } \\
\text { de acuerdo }\end{array}$ & De acuerdo & $\begin{array}{c}\text { En } \\
\text { desacuerdo }\end{array}$ & $\begin{array}{c}\text { Muy en } \\
\text { desacuerdo }\end{array}$ \\
\hline \multicolumn{5}{|c|}{\begin{tabular}{c|c} 
¿Los videos publicados en el padlet están & \\
relacionados con los contenidos teóricos de & \\
la asignatura? & \\
\end{tabular}} \\
\hline \multicolumn{5}{|l|}{$\begin{array}{l}¿ \text { ¿Te han resultado útiles los comentarios } \\
\text { realizados a tu publicación? }\end{array}$} \\
\hline \multicolumn{5}{|l|}{$\begin{array}{c}\text { ¿Ha sido satisfactorio el desarrollo de la } \\
\text { actividad propuesta? }\end{array}$} \\
\hline \multicolumn{5}{|l|}{$\begin{array}{c}\text { ¿Has empleado con anterioridad algún tipo } \\
\text { de pizarra electrónica? }\end{array}$} \\
\hline $\begin{array}{c}\text { ¿Emplearías pizarras electrónicas tipo } \\
\text { padlet en alguna otra asignatura? }\end{array}$ & & & & \\
\hline
\end{tabular}

Los resultados obtenidos en la encuesta acerca del grado de satisfacción de la actividad propuesta se muestran en la Figura 3. Como se observa en la figura, tanto el grado de satisfacción, como la utilidad de los videos y comentarios ha sido muy positiva para los alumnos. De hecho los alumnos afirman que considerarían positivo el empleo de pizarras electrónicas en futuras asignaturas.

Para concluir, el grado de satisfacción del profesor con la actividad propuesta fue muy elevado, ya que aumentó la motivación de los estudiantes para buscar contenidos audiovisuales relacionados con la asignatura impartida, además fue habitual durante el desarrollo de la clase hacer comentarios a algunos de los videos publicados en el padlet por 
los alumnos. A pesar que la participación fue bastante elevada durante el desarrollo de la actividad por la mayor parte de los alumnos, aproximadamente un 30\% del alumnado se esperó hasta el última día antes de finalizar el plazo para colgar el video y comentario correspondiente, indicando una baja motivación por cierta parte del alumnado que no se refleja en las encuestas realizadas. Finalmente, el ambiente generado fue positivo, ya que aumentó tanto la interrelación entre los estudiantes, como la relación estudiante alumno, y habitualmente se generaban debates antes del comienzo de la clase sobre los videos subidos a la pizarra electrónica.

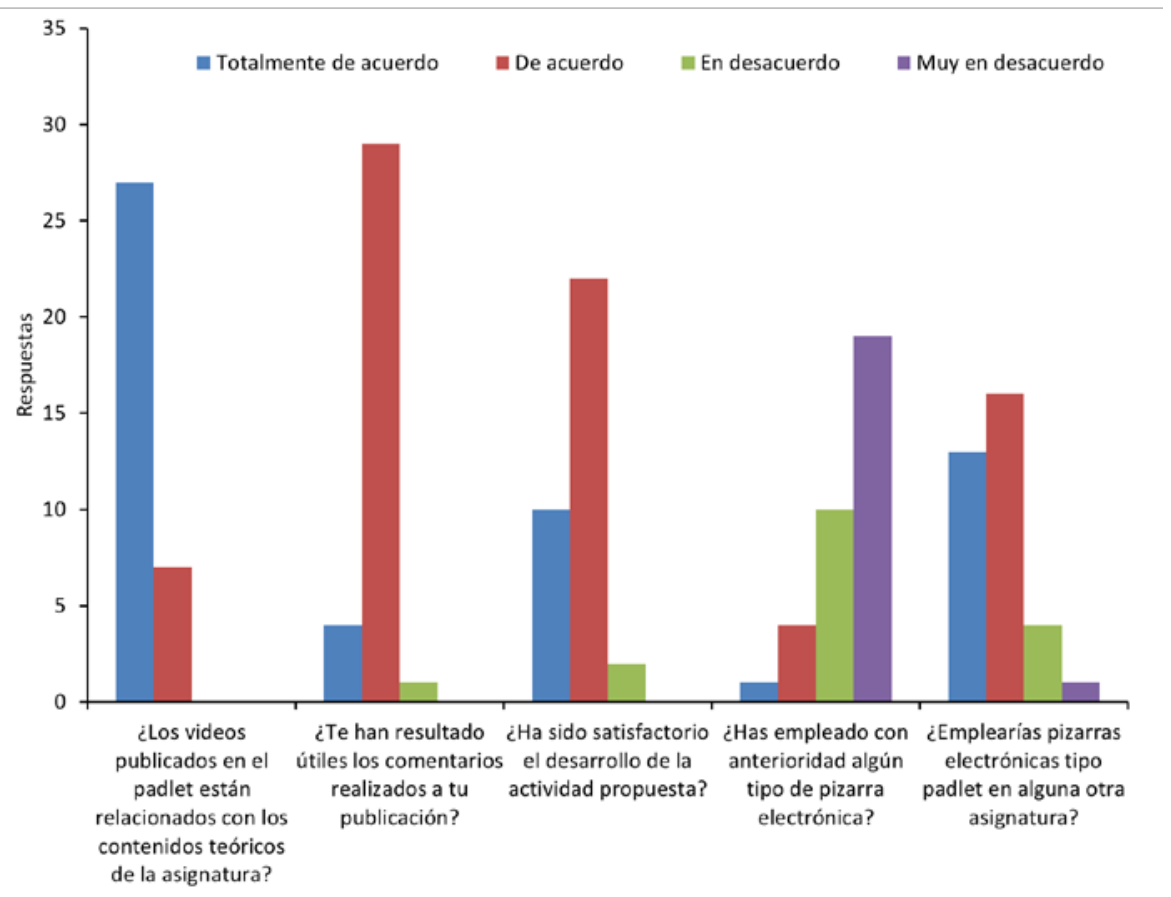

Fig.3 Resultado de la encuesta de grado de satisfacción de la actividad propuesta.

\section{Conclusiones}

Como conclusión, la experiencia ha resultado muy positiva, tanto para los alumnos como para el profesorado. Por una parte, se ha fomentado el trabajo colaborativo en lugar de fomentar un excesivo individualismo o competitividad. Por otra parte, se fomenta el interés por la asignatura y que sean los propios estudiantes los creadores de conocimiento, dejando su tradicional papel pasivo receptivo y adoptando una actitud más activa en el proceso de enseñanza/aprendizaje.

El haber creado un muro virtual en padlet ha brindado la posibilidad de cargar y compartir diversos contenidos multimedia como esquemas, imágenes, audios y videos en un muro de entorno digital y que estén fácilmente disponibles para los estudiantes pudiendo ser visualizados en cualquier momento. 
Los resultados obtenidos son preliminares. Para extraer conclusiones más realistas, se desarrollará esta actividad en cursos futuros y se podrá evaluar cuantitativamente su impacto a largo plazo en el proceso de enseñanza/aprendizaje de los alumnos.

\section{Referencias}

BERGMANN, J., SAMS, A. (2014). Dale la vuelta a tu clase: lleva tu clase a cada estudiante, en cualquier momento y cualquier lugar, Madrid: Biblioteca innovación educativa, Fundación Santa María-Ediciones SM.

GONZALEZ FRIAS, M.T., CRESPO-CABUTO, A., RIVERA-IRIBARREN, M. (2015). "Estudio de la percepción de los estudiantes sobre el uso de PADLET como apoyo a clases presenciales”, en Pizá Gutiérrez, R.I., Mortis Lozoya, S.V., González Román, M., Orduño Acosta, B.E. Resultados de interacción educativa. Méjico: Altexto, México.

HERNÁNDEZ, E., MEDINA, F. (2014). "La atención a la diversidad con la herramienta de innovación educativa GLOG” en Navarro, J., Gracia, M.D., Lineros, R., Soto, F.J. Claves para una educación diversa. Murcia: Consejería de Educación, Cultura y Universidades.

PALOMO LÓPEZ, R., RUIZ PALMERO, J., SÁNCHEZ RODRIGUEZ, J. (2007). Las TIC como agentes de innovación educativa. Sevilla: Junta de Andalucía, Consejería de Educación. 